\title{
Emerging Evidence of Mast Cell Involvement in Oral Squamous Cell Carcinoma
}

\author{
Simon Basha ${ }^{1}$, Nur Mohammad Monsur Hassan*1, Rahena Akhter ${ }^{3}$, Soichiro Ibaragi ${ }^{2}$, Tatsuo 0kui ${ }^{2}$, \\ Stephen $\operatorname{Cox}^{3}$ and Akira Sasaki ${ }^{2}$ \\ ${ }^{1}$ School of Dentistry and Health Sciences, Charles Sturt University, Orange, Australia \\ ${ }^{2}$ Department of Oral and Maxillofacial Surgery, Okayama University Graduate School of Medicine, Dentistry, and Pharmaceutical Sciences, \\ Kita-ku, Okayama, Japan \\ ${ }^{3}$ Faculty of Dentistry, The University of Sydney \\ *Corresponding author: Nur Mohammad Monsur Hassan, School of Dentistry \& Health Sciences, ${ }^{2}$ School of Community Health, \\ Charles Sturt University, Orange NSW 2800, Tel: Tel: +61 26365 7117; Email: nhassan@csu.edu.au
}

\section{ARTICLE INFO}

Received: 幽 March 13, 2019

Published: March 22, 2019

Citation: Simon Basha, Nur Mohammad Monsur Hassan, Rahena Akhter, Soichiro Ibaragi, Tatsuo Okui, Stephen Cox, Akira Sasaki. Emerging Evidence of Mast Cell Involvement in Oral Squamous Cell Carcinoma. Biomed J Sci \& Tech Res 16(2)-2019. BJSTR. MS.ID.002832.

\begin{abstract}
Objective: The purpose of this review is the discuss the current understanding of and concepts surrounding, the involvement of mast cells in Oral Squamous Cell Carcinoma.

Methods: We performed a search in Pubmed, limited to English language papers, using the keywords mast cells, oral cancer, Oral Squamous Cell Carcinoma, and complemented the search results with manual search of relevant cited articles within the search results. Each article was revised and summarised.

Results: Mast cell aggregation is increased around sites of Oral Squamous Cell Carcinoma, and frequently Mast Cell Density increases correlated with increased microvessel density in tumoural stroma, and increased levels of mast cells products promoting Extracellular Matrix remodeling, tumour mitogenicity and modulating host responses.
\end{abstract}

Conclusion: Mast cells can promote tumour proliferation and aggressiveness via a plethora of secreted molecules and raised levels of such secretions as well as mast cell aggregation at Oral Squamous Cell Carcinoma sites is implicit of their involvement in progression of the pathology. There lacks, however, correlative data in the literature between mast cells and clinicopathological features such as tumour size, regional nodal involvement, or metastasis.

\section{Mast Cells - as Sentinel Cells}

Mast Cells (MC) are tissue-resident, bone-marrow derived, granular sentinel cells. They enter circulation from the bone marrow as committed Mast Cell Progenitors (MCP) and undergo terminal differentiation in response to a stimulus. MC and their progenitors are found throughout connective tissues and the mucosae, though the highest MC densities are found in the skin, airways and digestive tract, that is, host-environment interfacescongruous with their role as sentinel cells [1].Two distinct subpopulations of MC have been identified in human tissues, classified according to the protease contents of their secretory granules-tryptase-only containing type, referred to as MCT, and chymase- and tryptase-containing type, referred to as MCTC [2].
The latter also contain other proteases, including cathepsin $\mathrm{G}$ and carboxypeptidase A. In addition to these proteases, MC possess an arsenal of effector molecules. These include molecules stored in secretory granules, such as heparin, serotonin, and histamine, and those which are synthesised de novo, such as leukotriene C4, prostaglandin D2, platelet activating factor, and an assortment of cytokines [3]. MC activation may precipitate degranulation, or only the release of select effector molecules, and may occur in response to IgE crosslinking, complement activation or certain toxins [4]. MC effectors may contribute to both physiological and pathological events. While these cells are well known as orchestrators of hypersensitivities and immune reactions, more recently the role of 
MC in modulating tumour growth-both positively and negatively has become a focus.

\section{Tissue Distribution, Activation and Migration of Mast Cells in Oral Cancer}

The altered tumour microenvironment induces changes in mast cell migration, activation and tissue distribution. Mast Cell Progenitors in peripheral tissue are under the influence of tumour-derived cytokines and chemoattractants controlling their maturation and migration. Stem Cell Factor (SCF), derived from the tumour cells, and its receptor c-Kit represent possibly the most significant and potent, and best characterised, mast cell chemotaxis and migration pathway. An increase in mast cell infiltration in areas of Oral Squamous Cell Carcinoma (OSCC) development has been demonstrated in a number of studies [5-12], and correlation between Mast Cell Density (MCD) and disease progression has also been reported [13-15]. In a slightly different vein Aromando, et al. [16] noted no change in total mast cell numbers in a hamster cheek pouch tissue during experimental carcinogenesis, but rather a decrease in MC in the adventitious tissue and an accumulation of MC in peritumoural and intratumoural stroma, as well as a reversion of the ratios of active/inactive $\mathrm{MC}$ in favour of the former [16]. Furthermore, differences in MCD between intratumoural and peritumoural stroma were evaluated, showing significantly higher MCD values in the peritumoural stroma than intratumoural, probably reflecting the migration of the cells from adventitious tissue as well as functional roles in Extracellular Matrix (ECM) degradation and induction of cell proliferation [16].

Further characterisation of MC subpopulations within the Intratumoural (IT) and Peritumoural (PT) stromal regions has shown that, while both MCTC and MCT counts are significantly increased throughout the tumoural stroma, MCTC type predominates in the PT stroma, while MCT subtype predominates in the intratumoural stroma [17]. The authors hypothesise that the distribution of subpopulations reflects functional requirements: MCTC contain chymase, which plays a role in activation of Pro-Matrix Metalloproteinase-2 (MMP-2) and Pro-Matrix Metalloproteinase-9 (MMP-9) to their active MMP-2 and MMP-9 forms, respectively [18]. Both MMP-2 and MMP-9 possess the capacity to degrade type IV collagen [19], a significant component of the basement membrane and barrier to tumour invasion. Hence, the localisation of MCTC at tumour peripheries suggests an ECM remodelling role for these cells. Similarly, MCT predominance in the IT stroma suggests a role of these cells and their potent angiogenic mediator, tryptase [20], in neovascularization of the tumour. In contrast, some studies of OSCC and other carcinomas have failed to demonstrate a statistically significant increase in MCD in tumour regions, or a decrease in MCD as the degree of differentiation decreases [21-23]. These results have on occasion been attributed to massive degranulation of the MC compromising visualization, or shortcomings in specificity of the toluidine blue staining protocol compared with antitryptase immunohistochemistry [23-,25]. Other studies have described a significant reduction in MC in cancers compared with controls $[12,25]$.

Putative causes of this decrease are tobacco exposure, shown in an experimental carcinogenesis model to accentuate a decrease in MC infiltration in tumours caused by 4-NQO [26], or a failure in migration of MC, indicated by the significantly decreased c-kit ${ }^{+} \mathrm{MC} /$ tryptase $\mathrm{e}^{+} \mathrm{MC}$ ratio, compared with control, attributable to changes within the tumour microenvironment [25] (the c-kit receptor on MC, together with its ligand SCF, are responsible for the migration, activation and maturation of MC [27]). However other authors have found no significant difference in c-kit ${ }^{+} /$tryptase $^{+}$ratio [25], suggesting no migration failure in such a case. Additionally, MC are present in neoplasms irrespective of the presence of inflammatory infiltrate, suggesting chemotactic pathways are selective for MC. Transforming growth factor-beta (TGF- $\beta$ ) is synthesised and released by MC, and is increased in OSCC [5]. Its local roles are pleiotropic, including: its initially cytotoxic, but progression of the pathology. There lacks, however, correlative data in the literature between mast cells and clinicopathological features such as tumour size, regional nodal involvement, or metastasis. Eventually cytokinetic role in tumourigenesis [25] its action as a potent chemotactic factor for MC [28]; its role in angiogenesis; and its supposed part role in mediating a phenotypical change in tumours from $\mathrm{CD}_{3} 4^{+}$fibrocytes to alpha-smooth muscle antigen ${ }^{+}\left(\alpha-\mathrm{SMA}^{+}\right)$ myofibroblasts [5].

Mangia et al. [29] report that tryptase can also induce phenotypic shift from $\mathrm{CD}_{3} 4^{+} / \alpha-\mathrm{SMA}^{-}$fibroblasts to CD34 $/ \alpha-\mathrm{SMA}^{+}$ myofibroblasts, lending further credence to the role of MC in this context. CD34+ fibrocytes express Granulocyte Macrophage ColonyStimulating Factor (GM-CSF) [30], which downregulates CD117 (c-Kit) expression in mast cells [31]; hence a phenotypic shift away from $\mathrm{CD}_{3} 4^{+}$fibrocytes as they differentiate to alpha-SMA myofibroblasts, decreases repression of CD117 expression and consequently, allows MC migration and infiltration [5].

\section{Mast Cells in Oral Cancer and Angiogenesis}

Angiogenesis and neoangiogenesis are the processes of formation of new blood vessels from pre-existing blood vessels, and formation de novo, respectively. Tumour proliferation is limited by oxygen perfusion, and tissue oxygen perfusion greater than $2 \mathrm{~mm}$ has been reported to be prohibitive of tumour growth [32]. Neovascularisation, therefore, is a process central to tumour growth and development, and has been implicated in dissemination and metastasis. Mast cells store and have the capacity to synthetise a number of angiogenic and neoangiogenic mediators, including angiopoietin-1, FGF-2, VEGF, IL-8, TGF- $\beta$, TNF- $\alpha$, histamine, heparin, tryptase and chymase, among others [33]. These mast cell mediators can act at various stages of angiogenesis including degradation of the ECM, migration and proliferation of endothelial cells, formation and distribution of new vessels, synthesis of ECM 
and pericyte mobilization $[34,35]$. It has been shown that during the initiation of angiogenesis, mast cell tryptase promotes ECM degradation through the activation of MMPs and plasminogen activator [36]. One quantification of the degree of tumour vascularisation is microvessel density. A number of studies have correlated mast cell densities with Microvessel Densities (MVD) in oral cancers [10,32,37-40].

Moreover, mast cell densities have been shown to increase with MVD as disease progresses, or degree of tumour differentiation decreases [41]. The distribution of MC within tissue is also indicative of functional roles. As described in section 2, Rojas et al. [42] characterized MC subpopulations in OSCC and determined that MCT were the predominant subtype in the intratumoural stroma, while MCTC were in the peritumoural stroma of OSCC. Separate studies have shown increases in MVD in the intratumoural stroma, while no significant increase was observed in peritumoural regions. This supports the hypothesis of Rojas et al. [42], that MCT are so localised for an angiogenic role via the known potent angiogenic factor, tryptase [41]. It has been shown that during the initiation of angiogenesis, mast cell tryptase can also promote ECM degradation through the activation of MMPs and plasminogen activator [36]. Data reporting the colocalisation of MC and blood vessels in oral cancer also suggest an intimate relationship between the pair and role in angiogenesis for MC in tumourigenesis [10]. While MC are implicated in neovascularization and are known to contain angiogenic factors, mechanisms are uncertain. The role of the potent angiogenic cytokine Vascular Endothelial Growth Factor (VEGF) contained in MC and released from tumour cells is not straightforward.

Several studies correlate MC with VEGF expression. Release of VEGF from MC is mediated in part by the interleukin-33/ST2 signalling axis [44]. IL-33 is upregulated in OSCC, and a correlation between IL-33 and MVD, as well as IL-33 and MCD has been reported, suggesting VEGF may be the intermediary [39]. However, the specific role of VEGF in MC-mediated angiogenesis is not clear. Artese et al. [46] showed that, in OSCC, while MVD was significantly increased in tumours and correlated with tumour grading, VEGF expression did not vary between OSCC and tumour-free controls, and no significant correlation between VEGF expression and MVD was observed. Carlile et al. [47] produced similar results in a similar study, noting that vascularity increased in OSCC compared with control, though this increase did not correlate with VEGF expression. Other studies have found significant VEGF expression increase in OSCC vs control, although VEGF expression did not directly correlate to MVD [32]. MCD did, however, correlate with MVD. A single-linkage cluster analysis on these three variables (MCD, MVD, VEGF expression) grouped VEGF expression and MVD, implying an indirect link between the two variables. Whereby, VEGF may recruit mast cells [48] which contain angiogenic factors $[32,49]$. Hence, VEGF indirectly induces angiogenesis. A more prominent and directly acting role for tryptase is therefore suggested $[50,51]$, seems to be confirmed by the results of Rojas et al. [42]. Yet interrelationship between MC and angiogenesis is not however a universal finding and we must state while the evidence is significant there remain many inconsistencies. Some authors, while finding a significant increase in MVD in SCC vs control, did not observe a correlation between MVD and MCD [52]. Other data as much as show the converse of the above - that is, increasing MVD inversely and significantly correlated with MCD [52].

\section{Mast Cells in Extracellular Matrix Remodelling in OSCC}

An important feature of cancer progression is the ability to degrade the Extracellular Matrix (ECM), and consequently permit proliferation and migration of cells, invasion of surrounding tissues and dissemination. Matrix Metalloproteinases (MMP) are endopeptidases responsible for degradation of the ECM. The MMPs can be categorized according to their preferred substrates, i.e. the collagenases (MMP-1, -8, -13), gelatinases (MMP-2, MMP9), stromelysins (MMP-3, MMP-10, MMP-11). Human mast cells interact with several MMP, both stimulatory and inhibitively, in ECM homeostasis [53]. Gelatinases A and B (MMP-2 and MMP-9, respectively) are secreted by MC $[54,55]$, or indirectly activated by MC-secreted chymase [54]. MC tryptase itself has also been shown to directly exert gelatinase-like activity [56], and tryptase is also involved in the processing and activation of MMP-3 and MMP-1, the latter being dependent on the activation of the former $[57,58]$. Chymase is also capable of directly activating MMP-1 and MMP-3 [59]. Further MC chymase, but not tryptase, may directly cleave procollagen to fibril-forming collagen [60]. Hence MC contribute both directly and indirectly to processes which degrade the ECM.

In the context of oral cancer, MMP-9 expression has been shown to be upregulated in OSCC compared with healthy tissues, and significantly correlated with MCD [61]. Another study showed lip SCC samples that expressed higher MC counts also showed increased collagen degradation, assayed by picro-sirius staining [7]. MMP-9 has been associated with aggressive tumour growth, proteolytic processing of the ECM and activation of cytokines (such as TGF- $\beta$ ) [10]. MMP-9 is capable of processing type IV collagen of the basement membrane [62] and other ECM components, which are key events in tumour invasion and metastasis (see Fig. 1). However, evidence supports a fluctuating role of MMP-9 in OSCC. High MMP-9 expression has been shown to correlate with nodal involvement and metastasis, and poor prognosis in OSCC [63]. Meanwhile, Guttman et al. [64] reported no correlation between MMP-9 and tumour size or nodal involvement. Similarly, other authors reported that MMP-9 expression was not associated with clinical variables, such as tumour stage, recurrence rate, etc. [65]. Other data suggest that MMP-2 and MMP-2 expression significantly correlates with collagen degradation and local invasiveness, though this was not related to metastatic potential of the disease [66]. Meanwhile, it has been suggested that although MMP-2 and MMP- 
9 expression is high in OSCC, the ratio of active/inactive MMP-9 is low, suggesting MMP-2 is the gelatinase of greater importance in OSCC [67]. Conversely, MCs have also been implicated in collagen deposition. Vidal et al. [10] observed the accumulation of MC in areas of fibrosis surrounding malignant minor salivary gland tumours and proposed the hypothesis that ECM remodelling, specifically collagen synthesis, may be mediated by MC.

A similar hypotheses have been made regarding odontogenic tumours [68] and breast cancers, in which it was suggested that tryptase played a role in collagen deposition [69]. Additionally, an association between MC and fibroblasts in the potentially malignant condition, oral submucous fibrosis, has been inferred [70,71]. Supporting these observations, MC products TGF- $\beta$ and tryptase have been shown to stimulate collagen deposition, fibroblast migration and fibroblast proliferation [20,72-77]. Hence, ECM homeostasis is a delicate balance between factors, which promote degradation, and proliferation. The tumour microenvironment may lead to unpredictable disruption of this balance.

\section{Mast Cells and Tumour Proliferation, Invasion and Dissemination}

Mast cells can precipitate mitogenicity in tumour cells directly through mediators, and indirectly through microenvironment modulation. The most abundant mast cell protease, tryptase, is implicated in promoting neoplastic cell proliferation via the Receptor Tyrosine Kinase (RTK) protease activated receptor 2 (PAR2 ), expressed on the surface of neoplastic cells. Tryptase cleaves and activates PAR-2, stimulating proliferation of receptor-bearing cells, as well as inducing the expression of cyclooxygenase-2 (COX-2) $[16,77]$. The proliferative consequence of tryptase-mediated PAR-2 activation has been reported in lung tissue, colon cancer and breast cancer $[76,78]$, but few studies exist correlating MC with tumour cell proliferation in OSCC, and those that fail do to demonstrate a significant correlation [7]. A study pertaining to the potentially malignant oral condition actinic cheilits has, however, quantified COX-2, PAR-2, MC and tryptase in human actinic cheilitis tissues. COX-2 is responsible for eicosanoid biosynthesis from arachidonic acid, and among the metabolites is Prostaglandin E2 (PGE2), which is also capable of promoting tumour proliferation [79]. The authors reported a significant correlation between tryptase-positive MC and PAR-2 expression, as well as COX-2 overexpression, inferring a role for tryptase in PAR-2 activation and COX-2 overexpression. Increased MC counts have also been associated with higher levels of DNA synthesis in an experimental hamster oral carcinogenesis model, again implicating tryptase-mediated PAR-2 activation [16].

\section{Conclusion}

Mast cells are influenced by, and influence, malignant tumours. They commonly accumulate in tumour-associated stroma and can promote tumour proliferation and aggressiveness via a plethora of secreted molecules. However, the literature is divided on the clinical significance of these local effects, and if or how they may represent or open up therapeutic possibilities. This variability in evidence suggests that a more complex set of interactions exists and overbears the net outcome and effects of mast cells in tumours. That is, while the mechanistic role of mast cells in cancer is becoming clearer and is seemingly becoming important, it is still incompletely understood. As such, conclusions about the role of mast cells in oral cancer would be fallacious to draw despite evidence correlating their accumulation with factors correlated with tumour progression.

\section{Acknowledgement}

a) Conflict of Interest: The authors declare that there are no conflicts of interest related to this letter. No external funding, apart from the support of the authors' institution, was available for this study.

Author Contributions: Basha S and Hassan NMM study concept, design, and preparation of the manuscript. Akhter R, Ibaragi S, Cox $\mathrm{S}$ and Sasaki A: help in manuscript preparation.

\section{References}

1. Grimbaldeston MA, Metz M, Yu M, Tsai M, Galli SJ (2006) Effector and potential immunoregulatory roles of mast cells in IgE-associated acquired immune responses. Current opinion in immunol 18(6): 751760 .

2. Irani AA, Schechter NM, Craig SS, De Blois G, et al. (1986) Two types of human mast cells that have distinct neutral protease compositions. Proc Natl Acad Sci 83(12): 4464-4468.

3. Gurish MF, Austen KF (2012) Developmental origin and functional specialization of mast cell subsets. Immunity 37(1): 25-33.

4. Wernersson S, Pejler G (2014) Mast cell secretory granules: armed for battle. Nature Rev Immunol 14(7): 478-494.

5. Barth PJ, Schenckzu Schweinsberg T, Ramaswamy A, Moll R (2004) CD34+ fibrocytes, alpha-smooth muscle antigen-positive myofibroblasts, and CD117 expression in the stroma of invasive squamous cell carcinomas of the oral cavity, pharynx and larynx. Virchows Arch 444(3): 231-234.

6. Gomes AP, Johann JE, Lovato GG, Ferreira AM (2008) Comparative analysis of the mast cell density in normal oral mucosa, actinic cheilitis and lip squamous cell carcinoma. Brazilian dental j 19(3): 186-189.

7. Costa NL, Oton Leite AF, Cheim Júnior AP, Alencar Rde C, Bittar GO, et al. (2009) Density and migration of mast cells in lip squamous cell carcinoma and actinic cheilitis. Histol Histopathol 24(4): 457-465.

8. Jaafari Ashkavandi Z, Khademi B, Akbari S, Malekzadeh M (2013) Serum Level of Mast Cell Tryptase in Patients with Oral Squamous Cell Carcinoma: Lack of Correlation with Clinicopathologic Factors. Asian Pac J Cancer Prev 14(5): 2955-2958.

9. Pyziak L, Stasikowska Kanicka O, Danilewicz M, Wągrowska Danilewicz M (2013) Immunohistochemical analysis of mast cell infiltrates and microvessel density in oral squamous cell carcinoma. Pol J Pathol 64(4): 276-280.

10. Vidal MT, De Oliveira Araújo IB, Gurgel CA, Pereira Fde A, Vilas Bôas DS, et al. (2013) Density of mast cells and microvessels in minor salivary gland tumors. Tumour Biol 34(1): 309-316.

11. Zaidi M, Mallick A (2014) A study on assessment of mast cells in oral squamous cell carcinoma. Ann Med Health Sci Res 4(3): 457-460.

12. Muniz JM, Bibiano Borges CR, Beghini M, De Araújo MS, Miranda Alves P, et al. (2015) Galectin-9 as an important marker in the differential diagnosis between oral squamous cell carcinoma, oral leukoplakia and oral lichen planus. Immunobiology 220(8): 1006-1011. 
13. Morris DR, Ding Y, Ricks TK, Gullapalli A, Wolfe BL, et al. (2006) Proteaseactivated receptor- 2 is essential for factor viia and xa induced signaling migration, and invasion of breast cancer cells. Cancer Res 66(1): 307314.

14. Sharma B, Sriram G, Saraswathi TR, Sivapathasundharam B (2010) Immunohistochemical evaluation of mast cells and angiogenesis in oral squamous cell carcinoma. Indian J Dent Res 21(2): 260-265.

15. Souza LR, Fonseca Silva T, Santos CC, Oliveira MV, Corrêa Oliveira R, et al. (2010) Association of mast cell, eosinophil leucocyte and microvessel densities in actinic cheilitis and lip squamous cell carcinoma. Histopathology 57(6): 796-805.

16. Aromando RF, Pérez MA, Heber EM, Trivillin VA, Tomasi VH, et al. (2008) Potential role of mast cells in hamster cheek pouch carcinogenesis. Oral Oncol 44(11): 1080-1087.

17. Rojas IG, Spencer ML, Martínez A, Maurelia MA, Rudolph MI (2005) Characterization of mast cell subpopulations in lip cancer. J oral pathology med 34(5): 268-273.

18. Tchougounova E, Lundequist A, Fajardo I, Winberg JO, Abrink M, et al. (2005) A Key role for mast cell chymase in the activation of pro-matrix metalloprotease-9 and pro-matrix metalloprotease-2. J Biol Chem 280(10): 9291-9296

19. Zeng ZS, Cohen AM, Guillem JG (1999) Loss of basement membrane type IV collagen is associated with increased expression of metalloproteinases 2 and 9 (MMP-2 and MMP-9) during human colorectal tumorigenesis. Carcinogenesis 20(5): 749-755.

20. Blair RJ, Meng H, Marchese MJ, S Ren, L B Schwartz, et al. (1997) Human mast cells stimulate vascular tube formation. Tryptase is a novel, potent angiogenic factor. J Clinical Investigation 99(11): 2691-2700.

21. Ranieri G, Labriola A, Achille G, Florio G, Zito AF, et al. (2002) Microvessel density, mast cell density and thymidine phosphorylase expression in oral squamous carcinoma. Int J Oncol 21(6): 1317-1323.

22. Cheema VS, Ramesh V, Balamurali PD (2012) The relevance of mast cells in oral squamous cell carcinoma. J Clin Diagn Res 6(10): 1803-1807.

23. Kalra M, Rao N, Nanda K, Kanwardeep Nanda, Farzan Rehman, et al. (2012) The role of mast cells on angiogenesis in oral squamous cell carcinoma. Med Oral Patol Oral Cir Bucal 17(2): e190-e196.

24. Batista A, Rodini C, Lara V (2005) Quantification of mast cells in different stages of human periodontal disease. Oral dis 11(4): 249-254.

25. Oliveira Neto HH, Leite AF, Costa NL, Alencar RC, Lara VS, et al (2007) Decrease in mast cells in oral squamous cell carcinoma: possible failure in the migration of these cells. Oral Oncol 43(5): 484-490.

26. Sand L, Hilliges M, Larsson P, Rajendrasinh R, Arpan K Shah, Sankalp $S$ (2001) Effects of long-term administration of cancer-promoting substances on oral subepithelial mast cells in the rat. Anticancer research 22(1): 2623-2627.

27. Galli SJ, Tsai M, Wershil BK, Tam SY, Costa JJ (1995) Regulation of mouse and human mast cell development, survival and function by stem cell factor, the ligand for the c-kit receptor. Int arch allergy immunol 107(1 3): 51-53.

28. Gruber BL, Marchese MJ, Kew RR (1994) Transforming growth factorbeta 1 mediates mast cell chemotaxis. J Immunol152(12): 5860-5867.

29. Mangia A, Malfettone A, Rossi R, Paradiso A, Ranieri G, et al. (2011) Tissue remodelling in breast cancer: human mast cell tryptase as an initiator of myofibroblast differentiation. Histopathology 58(7): 10961106.

30. Welker P, Grabbe J, Zuberbier T, Andreas Grützkau, Beate M Henz (2001) GM-CSF downmodulates c-kit, FceRI $\alpha$ and GM-CSF receptor expression as well as histamine and tryptase levels in cultured human mast cells. Archives of dermatological res 293(5): 249-258.

31. Michailidou EZ, Markopoulos AK, Antoniades DZ (2012) VEGF expression from human dysplastic or malignant oral epithelium may be related to mast cell density and the subsequent angiogenetic phenomena. Int J Oral Maxillofac Surg 41(12): 1467-1473.

32. Crivellato E, Nico B, Ribatti D (2008) Mast cells and tumour angiogenesis: New insight from experimental carcinogenesis. Cancer Lett 269(1): 1-6.

33. D’Amore P, Thompson R (1987) Mechanisms of angiogenesis. Annual rev physiol 49: 453-464.

34. Juczewska M, Chyczewski L (1996) Angiogenesis in cancer. Roczniki Akademii Medycznej w Bialymstoku 42: 86-100.

35. Stack MS, Johnson DA (1994) Human mast cell tryptase activates singlechain urinary-type plasminogen activator (pro-urokinase). J Biol Chem 269(13): 9416-9419.

36. Gaje P, Bocan V, Cîmpean AM, Izvernariu DA, Streian F, et al. (2007) Simultaneous demonstration of mast cells and blood vessels by the combined method CD34-alcian blue-safranin in lip tumors. Rom J Morphol Embryol 48(3): 237-241.

37. Mohtasham N, Babakoohi S, Salehinejad J, Montaser Kouhsari L, Shakeri MT, et al. (2010) Mast cell density and angiogenesis in oral dysplastic epithelium and low and high-grade oral squamous cell carcinoma. Acta Odontol Scand 68(5): 300-304.

38. Ciurea R, Mărgăritescu C, Simionescu C, Stepan A, Ciurea M (2011) VEGF and his R1 and R2 receptors expression in mast cells of oral squamous cells carcinomas and their involvement in tumoral angiogenesis. Rom J Morphol Embryol 52(4): 1227-1232.

39. Michailidou EZ, Markopoulos AK, Antoniades DZ (2012) VEGF expression from human dysplastic or malignant oral epithelium may be related to mast cell density and the subsequent angiogenetic phenomena. Int J Oral Maxillofac Surg 41(12): 1467-1473.

40. G Elpek, T Gelen, N Aksoy, A Erdogan, L Dertsiz, et al. (2001) The prognostic relevance of angiogenesis and mast cells in squamous cell carcinoma of the oesophagus. J clinical pathology 54(12): 940-944.

41. Shaik Dasthagirisaheb YB, Varvara G, Murmura G, Saggini A, Potalivo G, et al (2013) Vascular endothelial growth factor (VEGF), mast cells and inflammation. Int j immunopathology pharmacology 26(20): 327-335.

42. Ishikawa K, Yagi Nakanishi S, Nakanishi Y1, Kondo S, Tsuji A, et al. (2014) Expression of interleukin-33 is correlated with poor prognosis of patients with squamous cell carcinoma of the tongue. Auris Nasus Larynx 41(6): 552-557.

43. Artese L, Rubini C, Ferrero G, Fioroni M, Santinelli A, et al. (2000) Microvessel Density (MVD) and vascular endothelial growth factor expression (VEGF) in human oral squamous cell carcinoma. Anticancer research 21(1B): 689-695.

44. Carlile J, Harada K, Baillie R, Macluskey M, Chisholm DM, et al. (2001) Vascular endothelial growth factor (VEGF) expression in oral tissues: possible relevance to angiogenesis, tumour progression and field cancerisation. J oral pathology med 30(8): 449-457.

45. Gruber BL, Marchese MJ, Kew R (1995) Angiogenic factors stimulate mast-cell migration. Blood 86(7): 2488-2493.

46. Ribatti D, Crivellato E (2012) Mast cells, angiogenesis, and tumour growth. Biochimica et Biophysica Acta 1822(1): 2-8.

47. Iamaroon A, Pongsiriwet S, Jittidecharaks S, Pattanaporn K, Prapayasatok $S$, et al. (2003) Increase of mast cells and tumor angiogenesis in oral squamous cell carcinoma. J oral pathol med 32(4): 195-199.

48. Jahanshahi G, Sabaghian M (2012) Comparative immunohistochemical analysis of angiogenesis and mast cell density in oral normal mucosa and squamous cell carcinoma. Dent Res J (Isfahan) 9(1): 8-12.

49. Marichal T, Tsai M, Galli SJ (2013) Mast cells: potential positive and negative roles in tumor biology. Cancer Immunol Res 1(5): 269-279.

50. Fang KC, Wolters PJ, Steinhoff M, Bidgol A, Blount JL, et al. (1999) Mast cell expression of gelatinases $\mathrm{A}$ and $\mathrm{B}$ is regulated by kit ligand and TGF-ß. J Immunology 162(9): 5528-5535. 
51. Kanbe N, Tanaka A, Kanbe M, Itakura A, Kurosawa M, et al. (1999) Human mast cells produce matrix metalloproteinase 9. European J Immunology 29(8): 2645-2649.

52. Fajardo I, Pejler G (2003) Human Mast Cell $\beta$-Tryptase Is a Gelatinase. The Journal of Immunology, 171(3): 1493-1499.

53. Gruber BL, Marchese MJ, Suzuki K, Schwartz LB, Okada Y, et al. (1989) Synovial Procollagenase Activation by Human Mast-Cell Tryptase Dependence Upon Matrix Metalloproteinase-3 Activation. J Clin Invest 84(5): 1657-1662.

54. Lees M, Taylor DJ, Woolley DE (1994) Mast cell proteinases activate precursor forms of collagenase and stromelysin, but not of gelatinases A and B. Eur J Biochem 223(1): 171-177.

55. Saarinen J, Kalkkinen N, Welgus HG, Kovanen PT (1994) Activation of human interstitial procollagenase through direct cleavage of the Leu83Thr84 bond by mast cell chymase. J Biol Chem 269(27): 18134-18140.

56. Kofford MW, Schwartz LB, Schechter NM, Yager DR, Diegelmann RF, et al. (1997) Cleavage of Type I Procollagen by Human Mast Cell Chymase Initiates Collagen Fibril Formation and Generates a Unique Carboxylterminal Propeptide. Journal of Biological Chemistry 272(11): 7127 7131.

57. Souza Freitas V, De Andrade Santos PP, De Almeida Freitas R, Pereira Pinto L, De Souza LB (2011) Mast cells and matrix metalloproteinase 9 expression in actinic cheilitis and lip squamous cell carcinoma. Oral Surg Oral Med Oral Pathol Oral Radiol Endod 112(3): 342-348.

58. Katayama A, Bandoh N, Kishibe K, Takahara M, Ogino T, et al. (2004) Expressions of matrix metalloproteinases in early-stage oral squamous cell carcinoma as predictive indicators for tumor metastases and prognosis. Clinical Cancer Res 10(2): 634-640.

59. Guttman D, Stern Y, Shpitzer T, Ulanovski D, Druzd T, et al. (2004) Expression of MMP-9, TIMP-1, CD-34 and factor-8 as prognostic markers for squamous cell carcinoma of the tongue. Oral oncology 40(8): 798803.

60. De Vicente JC, Fresno MF, Villalain L, Vega JA, Hernández Vallejo G (2005) Expression and clinical significance of matrix metalloproteinase- 2 and matrix metalloproteinase- 9 in oral squamous cell carcinoma. Oral oncology 41(3): 283-293.

61. Ikebe T, Shinohara M, Takeuchi H, Mahiro Beppu, Shin ichi Kurahara, et al (1999) Gelatinolytic activity of matrix metalloproteinase in tumor tissues correlates with the invasiveness of oral cancer. Clin Experi metastasis 17(4): 315-322.

62. Kato K, Hara A, Kuno T, Kitaori N, Huilan Z, et al. (2005) Matrix metalloproteinases 2 and 9 in oral squamous cell carcinomas: manifestation and localization of their activity. J Cancer Res Clin Oncol 131(6): 340-346.

63. De Assis Caldas Pereira F, Gurgel CA, Ramos EA, Vidal MT, Pinheiro AL et al. (2012) Distribution of mast cells in benign odontogenic tumors. Tumour Biol 33(2): 455-461.

64. Huang S, Ling T, Wu H (1997) Experimental study on aqueous areca nut extracts inducing oral submucous fibrosis in rats. II. Effection of mast cells on collagen metabolism. Hua Xi Kou Qiang Yi Xue Za Zhi 15(2): 94 96.

\section{ISSN: 2574-1241}

DOI: 10.26717/BJSTR.2019.16.002832

Nur Mohammad Monsur Hassan. Biomed J Sci \& Tech Res

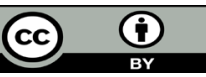

This work is licensed under Creative

Commons Attribution 4.0 License

Submission Link: https://biomedres.us/submit-manuscript.php
65. Pujari R, Vidya N (2013) Mast cell density in oral submucous fibrosis: a possible role in pathogenesis. Int J Health Sci 7(1): 23-29.

66. Fine A, Goldstein RH (1987) The effect of transforming growth factorbeta on cell proliferation and collagen formation by lung fibroblasts. J Biol Chem 262(8): 3897-3902.

67. Postlethwaite AE, Keski Oja J, Moses HL, Kang AH (1987) Stimulation of the chemotactic migration of human fibroblasts by transforming growth factor beta. J exp med 165(1): 251-256.

68. Cairns JA, Walls AF (1997) Mast cell tryptase stimulates the synthesis of type I collagen in human lung fibroblasts. J Clin Invest 99(6): 1313-1321.

69. Gruber BL, Kew RR, Jelaska A, Marchese MJ, Garlick J, et al. (1997) Human mast cells activate fibroblasts: tryptase is a fibrogenic factor stimulating collagen messenger ribonucleic acid synthesis and fibroblast chemotaxis. J Immunol 158(5): 2310-2317.

70. Abe M, Kurosawa M, Ishikawa O, Miyachi Y, Kido H (1998) Mast cell tryptase stimulates both human dermal fibroblast proliferation and type 1 collagen production. Clinical and Experimental Allergy, 28(12): 1509-1517.

71. Yoshii M, Jikuhara A, Mori S, Iwagaki H, Takahashi HK, et al. (2005) Mast cell tryptase stimulates DLD-1 carcinoma through prostaglandin-and MAP kinase-dependent manners. J pharmacol sci 98(40: 450-458.

72. Rojas IG, Martínez A, Brethauer U, Grez P, Yefi R, et al. (2009) Actinic cheilitis: epithelial expression of COX-2 and its association with mast cell tryptase and PAR-2. Oral Oncol 45(3): 284-290.

73. Aromando RF, Trivillin VA, Heber EM, Pozzi E, Schwint AE, et al. (2010) Early effect of boron neutron capture therapy mediated by boronophenylalanine (BPA-BNCT) on mast cells in premalignant tissue and tumors of the hamster cheek pouch. Oral Oncol 46(5): 355-359.

74. Akers IA, Parsons M, Hill MR, Hollenberg MD, Sanjar S, et al. (2000) Mast cell tryptase stimulates human lung fibroblast proliferation via protease-activated receptor-2. Am J Physiol Lung Cell Mol Physiol 278(1): 193-201.

75. Darmoul D, Marie JC, Devaud H, Gratio V, Laburthe M (2001) Initiation of human colon cancer cell proliferation by trypsin acting at proteaseactivated receptor-2. British J Cancer 85: 772-779.

76. Dubois RN, Abramson SB, Crofford L, Gupta RA, Simon LS, et al. (1998) Cyclooxygenase in biology and disease. The FASEB journal, 12(12): 1063-1073.

77. Frungieri MB, Weidinger S, Meineke V, Köhn FM, Mayerhofer A (2002) Proliferative action of mast-cell tryptase is mediated by PAR2, COX2, prostaglandins, and PPAR $\gamma$ : possible relevance to human fibrotic disorders. Proc Natl Acad Sci 99(23): 15072-15077.

78. Prime SS, Davies M, Pring M, Paterson IC (2004) The role of TGF- $\beta$ in epithelial malignancy and its relevance to the pathogenesis of oral cancer (part II). Critical Rev Oral Biol Med 15(6): 337-347.

79. Vilen ST, Salo T, Sorsa T, Nyberg P (2013) Fluctuating Roles of Matrix Metalloproteinase-9 in Oral Squamous Cell Carcinoma. The Scientific World Journal.

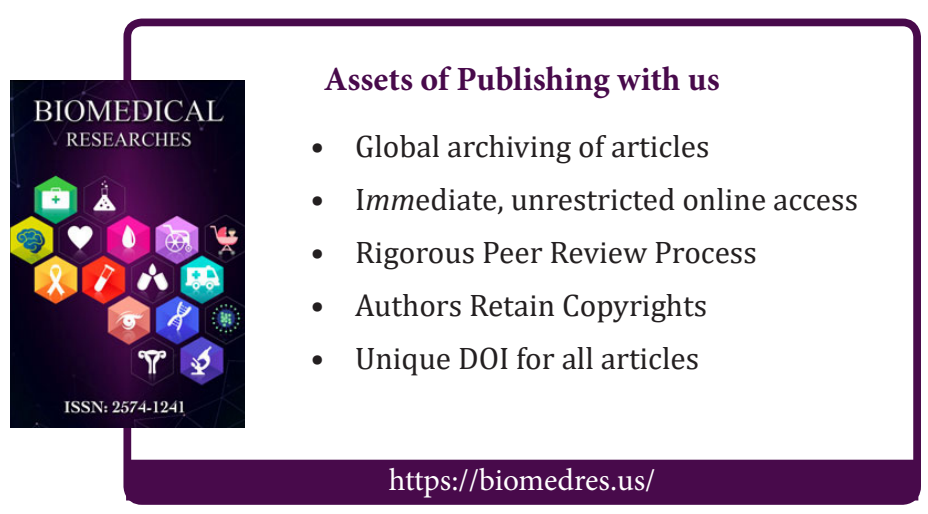

Copyright@ Nur Mohammad Monsur Hassan | Biomed J Sci \& Tech Res| BJSTR. MS.ID.002832. 